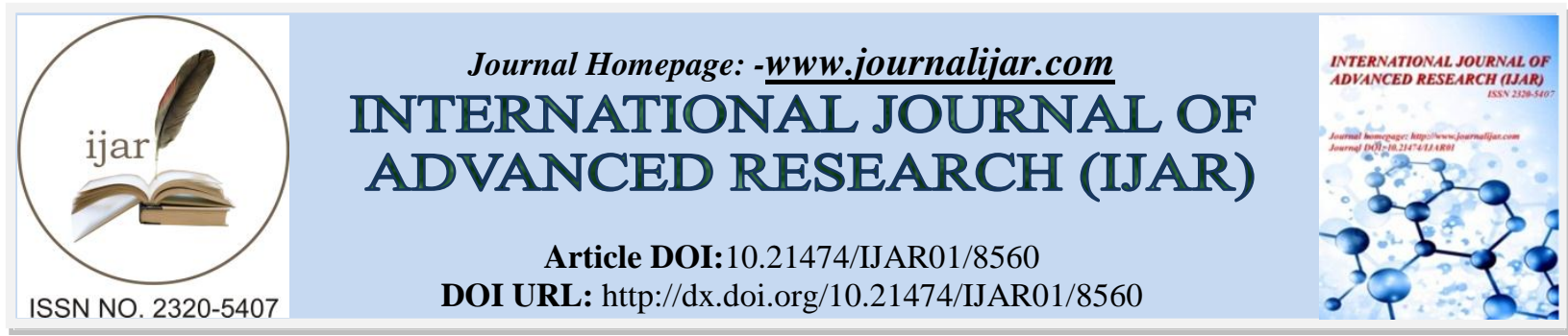

RESEARCH ARTICLE

\title{
IS DIET A CONTRIBUTING FACTOR FOR RECESSION.
}

\section{Manjunath Nandini ${ }^{1}$, Shetty Shilpa ${ }^{2}$, D Souza Melba $\mathbf{L}^{3}$, George Ria $\mathrm{S}^{4}$ and Muralidaran Gayathri ${ }^{5}$.}

1. Professor and Head of Department Department of Periodontics A.J Institute of Dental Sciences Mangalore.

2. Assistant Professor Department of Periodontics A.J Institute of Dental Sciences Mangalore.

3. Assistant Professor Department of Periodontics A.J Institute of Dental Sciences Mangalore.

4. Assistant Professor Department Of dental surgery Father Muller Medical College and hospital Mangalore.

5. Assistant professor Mamata dental college Khammam Telangana.

\section{Manuscript Info}

…......................

Manuscript History

Received: 14 December 2018

Final Accepted: 16 January 2019

Published: February 2019

Key words:-

Diet, Nutrition, Recession, Risk factor,

Brushing habits, Periodontal disease.

\section{Abstract}

Background: The role of nutrition in periodontal health and its effect on progression of disease is less established. Dietary components play a major role in the pathogenesis of dental caries, but play a modifying role in the progression of periodontal disease. Hence, the aim of the present study was to assess the effect of dietary influence on gingival recession.

Materials and method:330 patients visiting the outpatient Department of Periodontics(217 males and 113 females)were assessedfor their dietary habits and oral hygiene practices which were recorded in the form of aquestionnaire.Periodontal examination included assessment of gingival recession (Miller PD Jr. classification) and Community periodontal index modified was used to record the probing pocket depth and clinical attachment loss. The questionnaire was divided into nine groups. Group 1(type of diet), Group 2 (type of fruit), Group 3 (type of sauces), Group 4 (snack foods), Group 5 (sugar and its products), Group 6 (Special foods and aerated drinks), Group 7 (milk and its products), Group 8 (environmental factors)and Group 9 (brushing habits). These groups were further divided into sub categories.

Results: There was statistical significance to recession with progressing age $(\mathrm{p}<0.001)$. Group 1,2 and 3 had no statistical significance to recession. Statistical significance was found in the sub categories of group 4(potato snack),5(chocolate consumers),6(soft drinks and instant drinks),7(milk and frozen milk),8(tobacoo consumption-smoking and smokeless) and 9 (frequency of brushing).

Conclusion: Diet modifications have the potential to influence periodontal health and disease management by improving clinical outcomes as concluded from the present study.

Copy Right, IJAR, 2019,. All rights reserved.

\section{Introduction:-}

The role of nutrition in periodontal health is less established. A diet can produce both topical and systemic effects on the body and its tissues. Periodontal diseases are bacterial or inflammatory disorders that lead to destruction of the 
supporting tissues of the teeth. Although dietary components play a major role in the pathogenesis of dental caries, diet plays a modifying role in the progression of periodontal disease. ${ }^{1}$

Bacterial plaque is the primary initiating factor for periodontitis. ${ }^{2,3}$ Several other factors however were suggested to increase a person's susceptibility to developing periodontitis such as smoking and diabetes. ${ }^{4,5}$ Poor diet and inadequate nutrition were also suggested as possible risk factors for periodontitis. ${ }^{6}$

Gingival recession or marginal tissue recession is defined as the location of marginal tissue apical to CEJ with exposure of the root surface. ${ }^{7}$ Studies have shown a range in prevalence of gingival recession. Several dietary habits can itself induce gingival recession leading to attachment loss.

Diet is also known to be inflammatory diet (anti-inflammatory or pro-inflammatory). Poor diet is not likely to be sufficient or necessary in the pathogenesis of periodontal disease. However, diet may influence periodontal health by modifying the susceptibility of host immunity to infection rather than it being a primary etiological factor. ${ }^{6}$

Hence, the aim of the present study was to assess the effect of dietary influence on gingival recession.

\section{Materials and methods:-}

A total of 330 patients visiting the outpatient Department of Periodontics(217 males and 113 females) were examined and detailed information regarding the dietary habits and oral hygiene practices were recorded in the form of a questionnaire. Periodontal examination included gingival recession (MillerPD Jr. classification) and Community periodontal index modified was used to record the probing pocket depth and clinical attachment loss (Figure 1).

The data was collected and statistically analyzed using SPSS 17.0. Chi-square test was done for comparison of the parameters to recession. A $p$ value of $<0.005$ was considered to be statistically significant.

\section{Results:-}

Recession was assessed by dividing the various parameters into groups. Demographic data of age and gender was considered. The study was divided into nine groups and were as follows: Group 1 was type of diet (vegetarian or non- vegetarian), Group 2-type of fruit (citrus, tropical and dried), Group 3-type of sauces (gravies, pickles), Group 4-snack foods (potato and corn), Group 5-sugar and its products (honey, jams, chocolates and health bars and confectionaries), Group 6-Special foods (special dietary foods, instant food and processed food) and aerated drinks (soft drinks), Group 7-milk and its products (milk, yogurt, cream, cheese, frozen milk, flavored milk, tea and coffee), Group 8-environmental factors (smoking, tobacco chewing and pan chewing) and Group 9-brushing habits (type of bristle, stroke of brushing, dentifrice used, replacement of tooth brush, frequency of brushing and use of interdental aids). Periodontal status including recession was assessed with each of these groups.

When demographic data was assessed for age and gender attachment loss and recession was positively correlated in relation to age and was not significant with gender. No statistical significance was found in group 1 for recession (Graph 1, Table 1). On an average, among the various fruits consumed (Group 2) and type of sauces consumed (Group 3), there was no significant correlation for recession amongst the study population(Graph 2, Table 2).

When snacks containing either potato or corn were compared to recession, only the snacks containing potatoes showed statistical significance $(\mathrm{p}<0.001)($ Graph 2, Table 2).

Among group 5 of the study population, only the category who consumed chocolates showed statistical significance for recession (mainly in younger population)(Graph 2,3, Table 2,3).

There was moderate statistical significance in the category of group 6 and group 7 for soft drinks and instant drinks in group 6 and milk and frozen milk in group 7. However, other categories in the same groups like instant foods, special dietary foods, processed foods of group 6 and milk products (yogurt, cream, cheese and flavored milk) of group 7 did not show any statistical significance (Graph 3,4,5, Table 3,4,5). 
Group 8 which included environmental factors like smoking, tobacco chewing and pan chewing had statistical significance to recession (Graph 6, Table 6).

When all the brushing habits (Group 9) were considered only frequency of brushing had statistical significance for recession (Graph 7, Table 7).

\section{Discussion:-}

Dental conditions are usually overlooked by patients until pain or major oral symptoms are a major concern, whereas gingival recession is a visible dental change that is noted by patients and causes them to seek the advice of a dentist.

The significance of any gingival recession may vary considerably depending on the etiology, extent and associated symptoms in each case. This study aimed to investigate the relationship between diet and gingival recession. The dietary intake was classified into six groups and the remaining two groups consisted of environmental factors and oral hygiene measures.

Poor diet is not likely to be sufficient or necessary in the pathogenesis of periodontal disease. However, diet may influence periodontal health by modifying the susceptibility of individuals to infection rather than being the primary etiological factor. ${ }^{6}$ Adequate diet and nutrition have been suggested to improve the resistance of individuals toinfection and may also influence the virulence of periodontal pathogens. ${ }^{8}$ The type and amount of food consumed may influence plaque formation by providing the plaque bacteria with necessary nutrients or by altering their surrounding environment. ${ }^{9}$

Though a lot of studies have been done to evaluate the relationship of diet and dental caries, this study may be the first to examine relationship of diet to recession. Although dietary components play a major role in pathogenesis of dental caries, diet plays primarily a modifying role in progression of periodontal disease. ${ }^{1}$

Literature suggests that there is a relationship between the age of the experimental animal and extent of apical migration which supports the 1920s hypothesis that there is continuous passive eruption of teeth causing physiological recession. ${ }^{10,11}$ This is consistent with the findings of the present study which suggests that as age increases the prevalence of recession increases. There was no relation found between both the genders to recession.

Type of diet, either vegetarian or mixed, did not show any statistical significance to recession. But the results of an animal study on cats and dogs showed that feeding a dry food diet has a positive influence on oral health, decreasing the occurrence of dental deposits and periodontal disease. ${ }^{12}$ Another study stated that softer diet may promote plaque accumulation and subsequently contribute to the development of periodontal disease. ${ }^{13,14}$

Type of fruit (citrus, tropical or dried) did not have any correlation to recession. Certain studies revealed that some fruits tend to cause only moderate decrease in plaque pH.Apples, however, besides containing sometimes high concentrations of free acids, by virtue of their sugars content, can also give rise to formation of acid in plaque. ${ }^{15}$ Thus proving the popular saying 'an apple a day keeps the doctor away' may also apply to '...keeping the dentist away'. Types of savories did not have any correlation to recession.

Snack foods containing potato showed correlation to recession thus stating starch containing food may modify the plaque bacteria thus causing recession.

Sugar product consumed in the form of honey, jam and chocolates had an effect on recession. This was also proved by a study which concluded thatcereals, nuts and seeds, sugar and sweeteners and confectionery were related positively to dental plaque formation. ${ }^{16,17}$

Soft drinks and instant drinks had some significance for recession. This can be attributed to the fact that aerated drinks can cause tooth erosion thus creating plaque retentive areas.

Milk and frozen milk caused recession. This is not in par with the findings of the study which stated that foods that are rich in calcium are associated with lowerprevalence of periodontitis in United States population. ${ }^{2}$ Dairy productsare richer sources of several nutrients needed for bone development and maintenance such as calcium, 
phosphorus, magnesium, potassium, zinc, protein, vitamin $\mathrm{D}$ etc.The ratio of calcium to phosphorus in dairy product is optimal for building bone tissues.Calcium was hypothesized to have indirect effect on periodontal condition through regulation of skeletal and alveolar bone density. ${ }^{18}$

Environmental factors like nicotine in any form (smokeless or smoking) had significant correlation to recession.This is a well proven fact that patient who smoke have more gingival recession due to the hypothesis that smoking causes systemic alterations in the immune response or local changes such as a reduction in gingival blood flow thus causing recession. ${ }^{19}$

A study stated that increased frequency of brushing is a factor for recession along with the type of brush and simple brushing techniques; $;^{10}$ although this study could only prove that the frequency of brushing had a direct correlation to recession.

Thus nutrients act as a double edge sword. It is reasonable to consume a nutritionally adequate diet to help maintain host resistance and to maintain the integrity of the periodontal tissues. A good diet contributes to both good general health and good oral health. Consumption of diet that focuses on reducing our intake of refined carbohydrates and includes eating more whole grains, fruits, vegetables and dietary sources of calcium is required. ${ }^{1}$

A diet that consists of right amount of essential nutrients such as carbohydrates, proteins, fats, vitamins, minerals, roughage and water required by the body is called a balanced diet. The recommendations of the 2011 European workshop on Periodontology suggest that the dental team should consider including advice to all patients on increasing levels of fish oils, fiber, fruit and vegetables and to reduce levels of refined sugars as part of a periodontal prevention/ treatment regime and a general health benefit message. ${ }^{20,21}$

\section{Conclusion:-}

Diet modifications have the potential to influence periodontal disease management by improving clinical outcomes.There is, however, insufficient evidencetojustify as to how diet influences the progression of recession. Future research should focus on an evaluation of which foods and nutrients may help to prevent the onset and the progression of oral diseases.

\section{Limitations:-}

1. A semi-quantitative food frequency questionnaire was used to determine quantitative food intake.

2. Food intake records may not provide a complete picture of what is being eaten on a routine basis.

3. Precise weighing methods are not possible to measure the amount of nutrients consumed.

4. Could not confirm a clear cause-effect relationship between nutrition and periodontal diseasebecauseof a lack of longitudinal studies.

5. To explore the actual relationship, further prospective studies and clinical trials will be necessary.

Graph 1:-Correlation between recession and demographic data and Group 1.

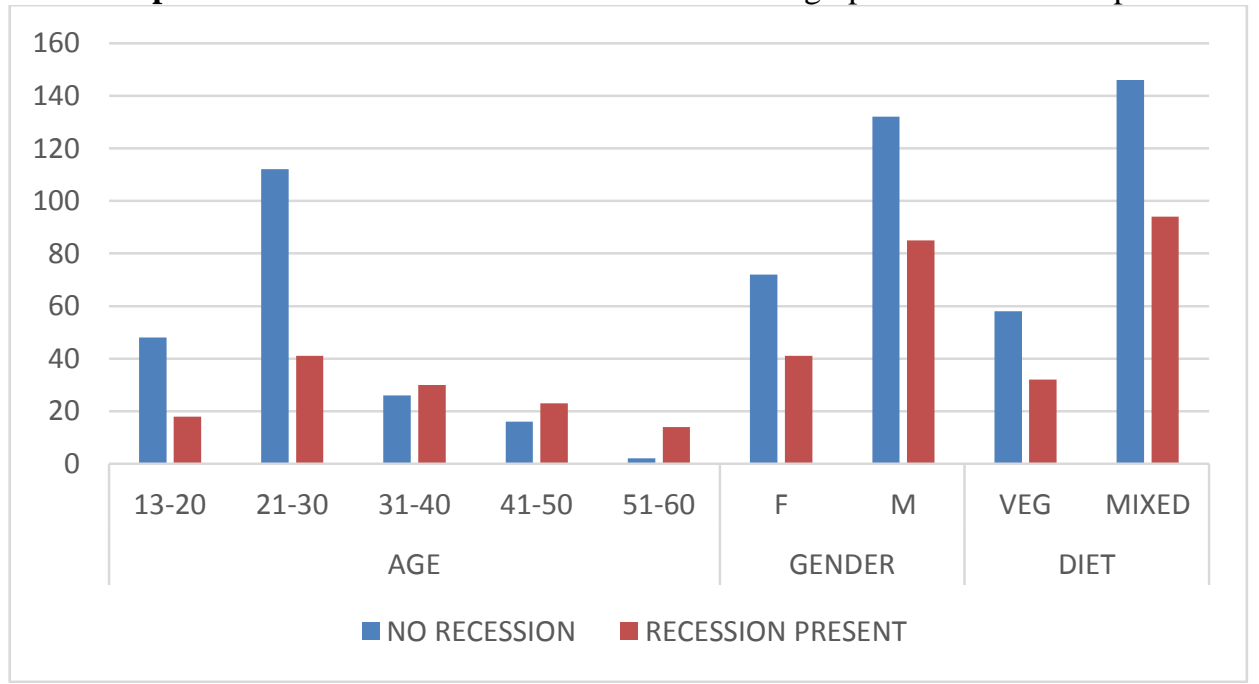


Table 1:-Correlation between recession and demographic data and Group 1

\begin{tabular}{|c|c|c|}
\hline \multirow[t]{2}{*}{$\begin{array}{l}\text { Demographic } \\
\text { data }\end{array}$} & $\begin{array}{l}\text { Age } \\
13-20 \\
21-30 \\
31-40 \\
41-50 \\
51-60 \\
\end{array}$ & $\begin{array}{l}\text { p value } \\
<0.001\end{array}$ \\
\hline & $\begin{array}{l}\text { Gender } \\
\text { Male } \\
\text { Female }\end{array}$ & 0.608 \\
\hline Group 1 & $\begin{array}{l}\text { Diet } \\
\text { Veg } \\
\text { Mixed }\end{array}$ & 0.548 \\
\hline
\end{tabular}

Graph 2:-Correlation between recession and Groups 2,3,4,5

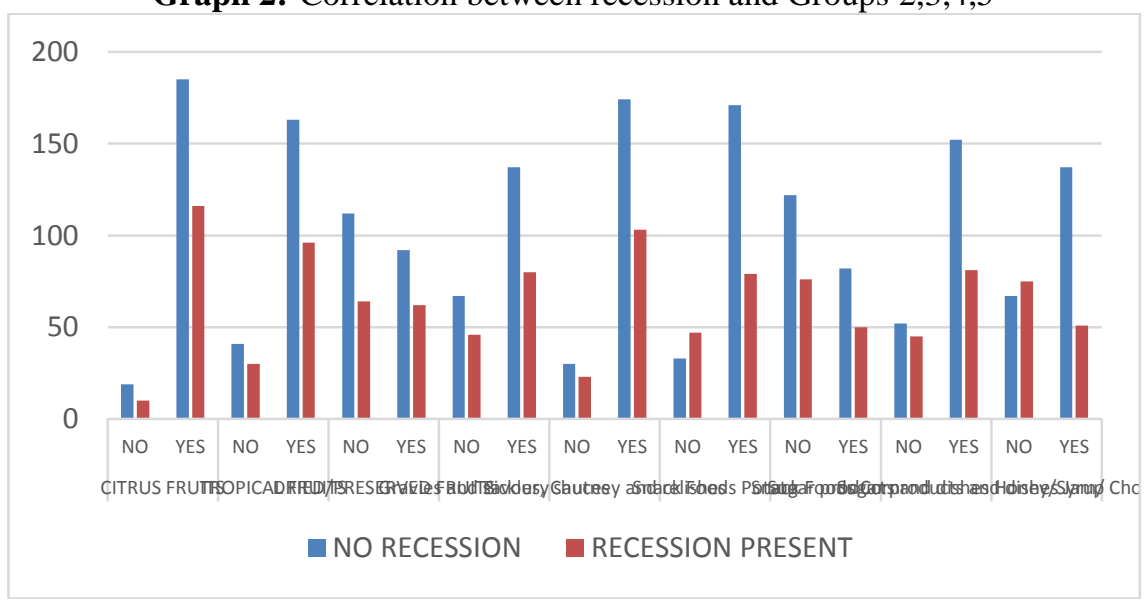

Table 2:-Correlation between recession and Groups 2,3,4,5

\begin{tabular}{|l|l|l|}
\hline Groups & Type of food & P value \\
\hline \multirow{4}{*}{ Group 2 } & Citrus fruits & 0.668 \\
\cline { 2 - 3 } & Tropical fruits & 0.425 \\
\cline { 2 - 3 } & Dried/Preserved fruits & 0.467 \\
\hline \multirow{3}{*}{ Group 3 } & Gravies and savoury sauces & 0.495 \\
\cline { 2 - 3 } & Pickles, Chutney and relishes & 0.394 \\
\hline \multirow{2}{*}{ Group 4 } & Snack food potato & $\mathbf{< 0 . 0 0 1}$ \\
\cline { 2 - 3 } & Snack food corn & 0.926 \\
\hline \multirow{2}{*}{ Group 5 } & Sugar product and dishes honey/ syrup & $\mathbf{0 . 0 4 8}$ \\
\cline { 2 - 3 } & Sugar product and dishes jam/ Chocolate & $\mathbf{< 0 . 0 0 1}$ \\
\hline
\end{tabular}

Graph 3:-Correlation between recession and Groups 5,6

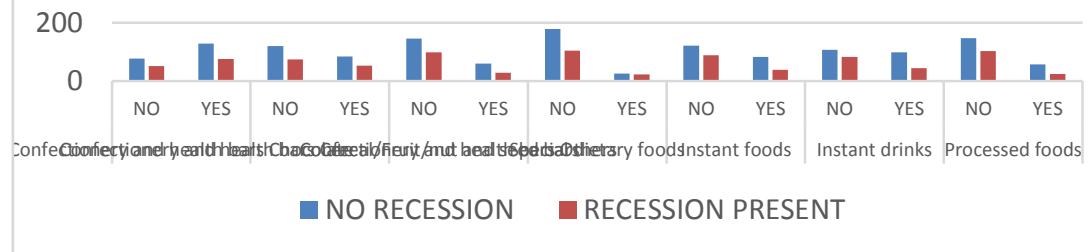


Table 3:-Correlation between recession and Groups 5,6

\begin{tabular}{|l|l|l|}
\hline Groups & Type of food & P value \\
\hline \multirow{4}{*}{ Group 5 } & Confectionary health bar and chocolate & 0.559 \\
\cline { 2 - 3 } & Cereal/ fruit/ nuts and seeds & 0.987 \\
\cline { 2 - 3 } & Confectionary health bars & 0.18 \\
\hline \multirow{3}{*}{ Group 6 } & Special dietary foods & 0.238 \\
\cline { 2 - 3 } & Instant foods & 0.054 \\
\cline { 2 - 3 } & Instant drinks & $\mathbf{0 . 0 1 9}$ \\
\cline { 2 - 3 } & Processed food & 0.068 \\
\hline
\end{tabular}

Graph 4:-Correlation between recession and Group 7

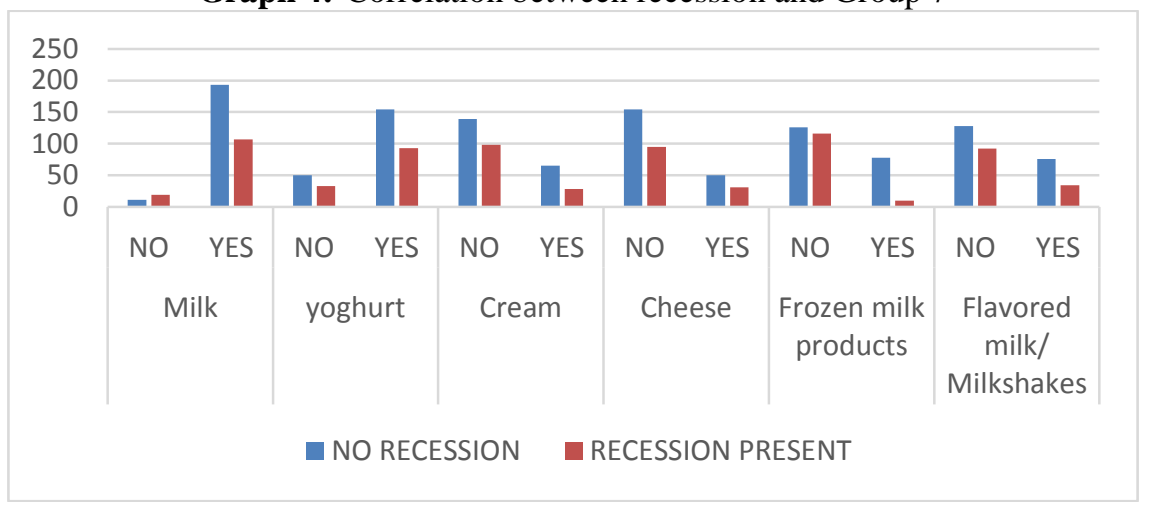

Table 4:-Correlation between recession and Group 7

\begin{tabular}{|l|l|l|}
\hline Groups & Type of food & P value \\
\hline \multirow{4}{*}{ Group 7 } & Milk & 0.003 \\
\cline { 2 - 3 } & Yogurt & 0.732 \\
\cline { 2 - 3 } & Cream & 0.059 \\
\cline { 2 - 3 } & Cheese & 0.985 \\
\cline { 2 - 3 } & Frozen milk products & $<\mathbf{0 . 0 0 1}$ \\
\cline { 2 - 3 } & Flavoured milk/ milkshake & 0.054 \\
\hline
\end{tabular}

Graph 5:-Correlation between recession and Groups 6,7

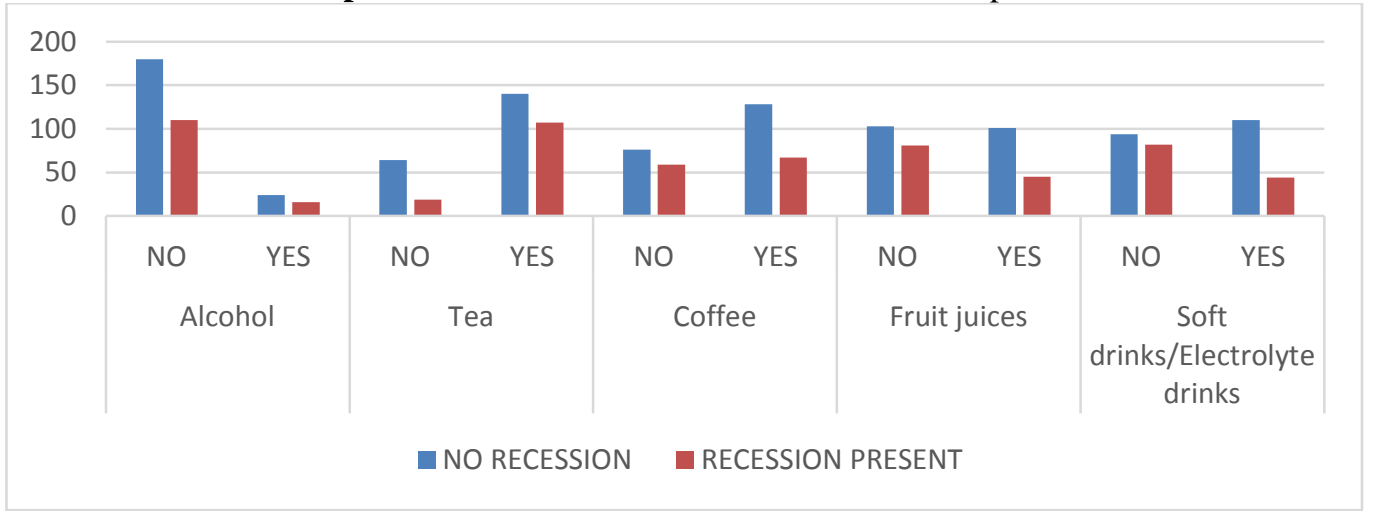

Table 5:-Correlation between recession and Groups 6,7

\begin{tabular}{|l|l|l|}
\hline Groups & Type of food & P value \\
\hline \multirow{3}{*}{ Group 7} & Tea & $\mathbf{0 . 0 0 1}$ \\
\cline { 2 - 3 } & Coffee & 0.086 \\
\cline { 2 - 3 } & Fruit juice & $\mathbf{0 . 0 1 4}$ \\
\hline
\end{tabular}




\begin{tabular}{|l|l|l|}
\hline Group 6 & Soft drinks and electrolytes & $\mathbf{0 . 0 0 1}$ \\
\hline
\end{tabular}

Graph 6:-Correlation between recession and Group 8

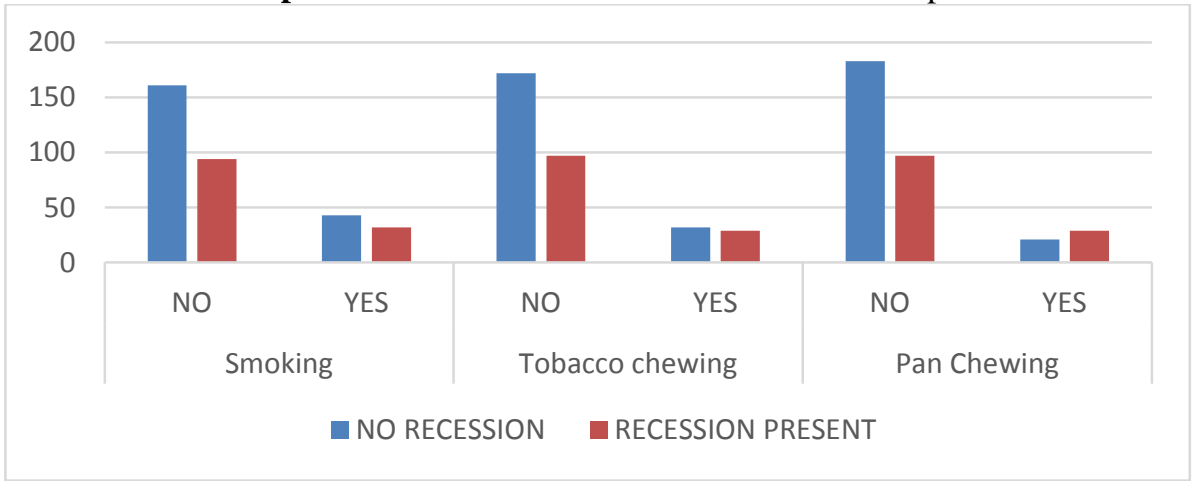

Table 6:-Correlation between recession and Group 8

\begin{tabular}{|l|l|l|}
\hline Groups & Type of food & P value \\
\hline \multirow{3}{*}{ Group 8} & Smoking & 0.363 \\
\cline { 2 - 3 } & Tobacco chewing & 0.096 \\
\cline { 2 - 3 } & Pan chewing & $\mathbf{0 . 0 0 2}$ \\
\cline { 2 - 3 } & Alcohol & 0.801 \\
\hline
\end{tabular}

Graph 7:-Correlation between recession and Group 9

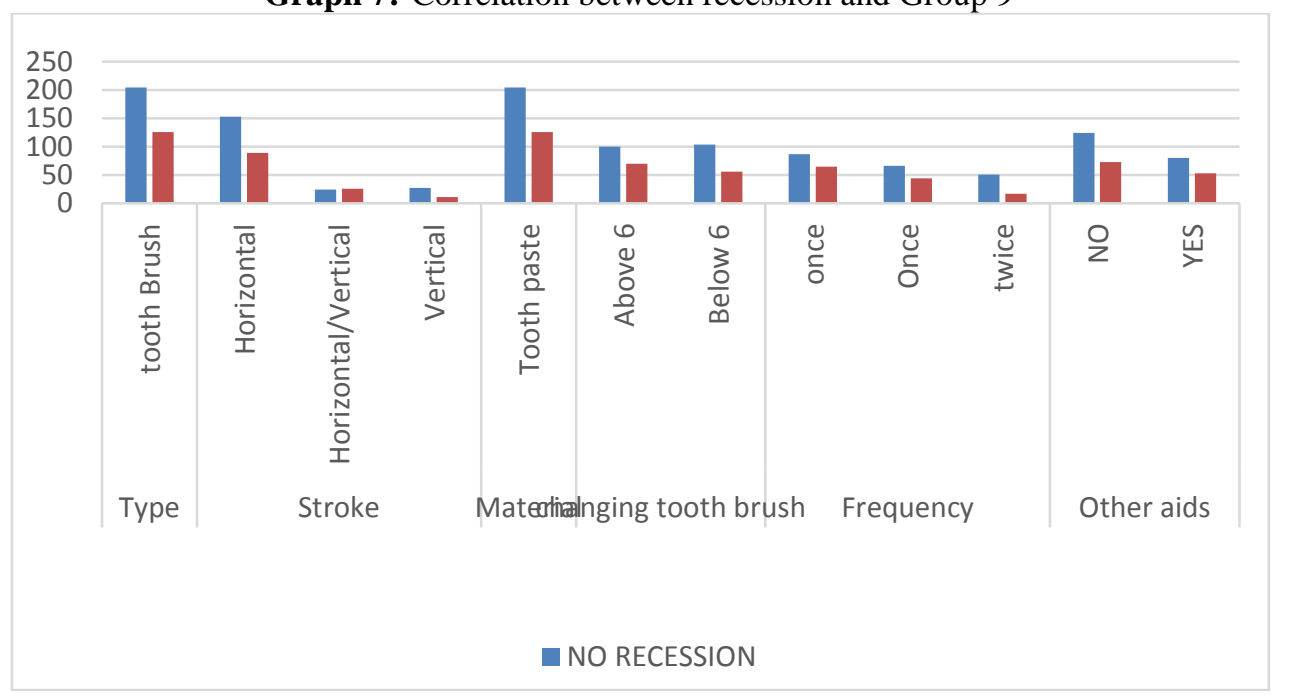

Table 7:-Correlation between recession and Group 9

\begin{tabular}{|l|l|l|}
\hline Groups & Oral hygiene practices & P value \\
\hline \multirow{4}{*}{ Group 9 } & Type & - \\
\cline { 2 - 3 } & Stroke & 0.06 \\
\cline { 2 - 3 } & Material & - \\
\cline { 2 - 3 } & Changing toothbrush frequency & 0.248 \\
\cline { 2 - 3 } & Frequency & 0.039 \\
\cline { 2 - 3 } & Other interdental aids & 0.608 \\
\hline
\end{tabular}




\section{References:-}

1. Schifferle RE. Periodontal disease and nutrition: separating the evidence from current fads. Periodontol 2000 2009;50:78-89.

2. Al-Zahrani MS. Increased intake of dairy products is related to lower periodontitis prevalence. $\mathrm{J}$ Periodontol 2006;77:289-94.

3. AmericanAcademyofPeriodontology.Thepathogenesis of periodontal diseases (position paper). J Periodontol 1999;70:457-470.

4. Genco RJ. Current View of Risk Factors for Periodontal Diseases. J Periodontol 1996;67(Suppl.):1041-9.

5. Albandar JM. Global risk factors and risk indicators for periodontal diseases. Periodontol 2000 2002;29:177206.

6. Alfano MC. Controversies, perspectives, and clinical implications of nutrition in periodontal disease. Dent Clin North Am 1976;20:519-48.

7. Lindhe J, Lang NP, Karring T. Clinical periodontology and implant dentistry. $5^{\text {th }}$ edition. Blackwell Munksgaard;2008.

8. Boyd LD, Madden TE. Nutrition, infection, and periodontal disease. Dent Clin North Am 2003;47:337-354.

9. Bowden GH, Li YH. Nutritional influences on biofilm development. Adv Dent Res 1997;11:81-99.

10. Tugnait A, Clerehugh V. Gingival recession —its significance and management. J Dent 2001;29:381-94.

11. Klingsberg J, Butcher EO. Comparative histology of age changes in oral tissues of rat, hamster, and monkey. $\mathbf{J}$ Dent Res 1960;39:158-69.

12. Gawor JP, Reiter AM, Jodkowska K, Kurski G, Wojtacki MP, Kurek A. Influence of diet on oral health in cats and dogs. J Nutri 2006;136:2021S-3S.

13. Al-Zahrani MS,Borawski EA, Bissada NF. Periodontitis and Three Health-Enhancing Behaviors: Maintaining Normal Weight, Engaging in Recommended Level of Exercise, and Consuming a High-Quality Diet. J Periodontol2005;76:1362-66.

14. Newman HN. Diet, attrition, plaque and dental disease. Br Dent J 1974;136:491-497.

15. Konig KG, Nijmegen. Diet and oral health. Int Dent J 2000;50:162-174.

16. Yoshihara A, Watanabe R, Hanada N, Miyazaki H. A longitudinal study of the relationship between diet intake and dental caries and periodontal disease in elderly Japanese subjects. Gerodontology 2009;26:130-136.

17. Papas AS, Joshi A, Palmer CA, Giunta JL, Dwyer JT. Relationship of diet to root caries. Am J Clin Nutr 1995;61: 423S- 429S.

18. Heaney RP. Calcium, dairy products and osteoporosis. J Am Coll Nutr2000;19(Suppl.):83S-99S.

19. Gunsolley JC, Quinn SM, Tew J, Gooss CM, Brooks CN, Schenkein HA. The effect of smoking on individuals with minimal periodontal destruction. J Periodontol 1998;69:165-70.

20. Chapple ILC, Milward MR. The role of diet in periodontal disease. Clin 2013;52:18-21.

21. Chapple ILC, Milward MR, Ling-Mountford N, Weston P, Carter K, Askey K et al. Adjunctive daily supplementation with encapsulated fruit, vegetable and berry juice powder concentrates and clinical periodontal outcomes: a double-blind RCT. J Clin Periodontol 2012;39:62-72. 